\title{
Adenolipoma da glândula tireoide: relato de caso
}

Primeira submissão em 03/10/11 Última submissão em 13/03/12

\section{Adenolipoma of the thyroid gland: a case report}

Gustavo Soares Corrêa Silva'; Sérgio Almeida Pinheiro Chagas²; Maurício Buzelin Nunes³; Rodrigo Assis de Paula

\section{unitermos}

Tireoide

Adenolipoma

Patologia

\section{resumo}

Os adenolipomas tireoidianos são neoplasias raras e benignas, compostas de tecido adiposo maduro e folículos tireoidianos, de histogênese ainda indefinida, que acometem geralmente pacientes adultas do sexo feminino. Relata-se um caso de adenolipoma tireoidiano em paciente feminina de 65 anos de idade, discutindo-se os aspectos clínicos e laboratoriais e o diagnóstico diferencial.

\section{abstract}

Adenolipomas of the thyroid gland are rare and benign neoplasms composed of mature adipose tissue and thyroid follicles, with histogenesis still unknown. It commonly affects adult female patients. We report a case of adenolipoma of the thyroid gland in a 65 year-old female patient and discuss its clinical and laboratorial aspects and differential diagnosis. key words

Thyroid

Adenolipoma

Pathology

1. Médico residente de Anatomia Patológica do Hospital Santa Casa de Belo Horizonte.

2. Patologista do Hospital Santa Casa de Belo Horizonte.

3. Patologista do Instituto Moacyr Junqueira; assistente efetivo do Laboratório de Anatomia Patológica do Hospital Santa Casa de Belo Horizonte.

4. Patologista do Laboratório Hugo Silviano Brandão. 


\section{Introdução}

Os adenolipomas tireoidianos consistem em neoplasias benignas raras, indolentes, apresentando características clínicas, como massa cervical de limitações precisas, consistência elástica e não aderente a planos profundos, à palpação. São endocrinologicamente inativas e geralmente acometem mulheres com idade média de 53,4 anos $^{(7,11)}$ com o perfil de exames laboratoriais na normalidade. A histogênese ainda é obscura; entretanto, várias hipóteses sugerem provável origem neoplásica. Sua constituição histológica é de tecido tireoidiano, formando nódulos e exibindo ilhotas de tecido adiposo unilocular maduro espalhadas pelo parênquima, em localizações intra e interfoliculares. Métodos de imagem podem proporcionar e sugerir o diagnóstico, contudo, a análise histopatológica representa o padrão-ouro para o diagnóstico definitivo ${ }^{(6,8)}$.

\section{Relato de caso}

Paciente M. J. S., do sexo feminino, 65 anos de idade, foi referenciada à consulta endocrinológica no Centro de Especialidades Médicas de Belo Horizonte (CEM), queixando-se de aumento do volume cervical e disfagia ocasional.

A paciente era portadora de hipertensão arterial sistêmica e diabetes mellitus, mas apresentava controle clínico adequado com terapia medicamentosa.

Relatava ausência de história pregressa de doença tireoidiana familiar. Ao exame físico, identificou-se à palpação da região cervical anterior direita nodulação de consistência elástica, indolor e móvel, sem aderências a planos profundos. Não foram identificadas linfadenopatias regionais. Os exames laboratoriais confirmaram o estado eutireoideu por meio da dosagem de tri-iodotironina (T3) e tiroxina (T4) livres e hormônio tireoestimulante (TSH). A pesquisa de anticorpos antirreceptores de TSH, antitireoglobulina e antitireoperoxidase resultou negativa. A ultrassonografia de região cervical anterior mostrou tireoide com dimensões anormais em lobo direito e heterogenicidade estrutural, multinodular, evidenciando o maior nódulo em lobo tireoidiano direito, medindo $3,5 \mathrm{~cm}$.

Foi realizada punção aspirativa por agulha fina (PAAF) do nódulo, cujo resultado do exame citopatológico sugeriu bócio coloide. Devido à sintomatologia, a paciente foi avaliada pela equipe de cirurgia geral, a qual indicou intervenção cirúrgica. A paciente foi submetida à tireoidectomia total, sem intercorrências durante o procedimento. A peça cirúrgica foi enviada para estudo anatomopatológico, que, ao exame macroscópico, revelou lobo direito tireoidiano recebido parcialmente seccionado, medindo $8 \times 5 \times 4,3 \mathrm{~cm}$ e pesando $79 \mathrm{~g}$. Apresentava superfície externa lisa e superfície de corte pardo-clara, macia e brilhante, com áreas sugestivas de calcificação e nódulo de limites precisos, medindo $4 \times 2,5 \times 2,2 \mathrm{~cm}$, de consistência elástica.

O lobo esquerdo tireoidiano media 4,8 $\times 3,1 \times 1,2 \mathrm{~cm} \mathrm{e}$ pesava $10 \mathrm{~g}$. Apresentava superfície externa lisa e superfície de corte pardo-clara, macia e brilhante com áreas nodulares, bem circunscritas, medindo até $0,8 \mathrm{~cm}$ de diâmetro.

Ao exame microscópico, os cortes histológicos estudados, em coloração de rotina (hematoxilina e eosina [HE]), evidenciaram, em lobo direito, lesão nodular bem delimitada por cápsula fibrosa, constituída por folículos tireoidianos de tamanhos variados revestidos por epitélio cuboidal sem atipias, contendo coloide. Notou-se ainda tecido adiposo unilocular localizado em regiões intra e perifoliculares, compatíveis com o diagnóstico de adenolipoma tireoidiano (Figuras 1 e 2). Invasão neurovascular e capsular não foi observada.

O restante do parênquima analisado apresentava bócio multinodular com formação de macrofolículos. A paciente está em controle clínico e laboratorial, eutireoidea e em uso de levotiroxina, $125 \mu \mathrm{g} / \mathrm{dia}$.

\section{Discussão}

Conhecidos como tireolipomas, tireoamartomas ${ }^{(1)}$ ou lipoadenomas, essas lesões constituem neoplasias benignas raras, apresentando tecido adiposo unilocular permeando

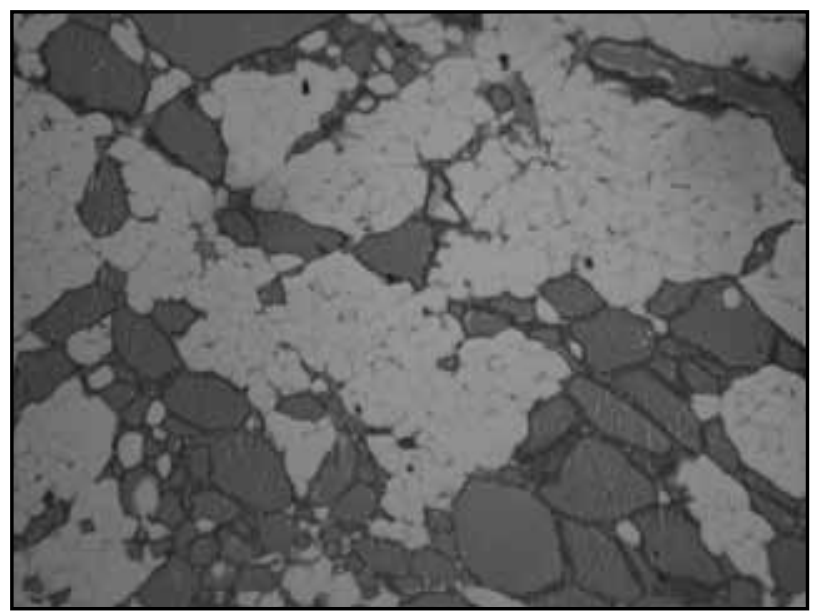

Figura 1 - Adenolipoma de tireoide (HE 40X)

Comprometimento difuso do nódulo tireoidiano; folículos com coloide e substância clara associada.

$H E$ : hematoxilina e eosina. 


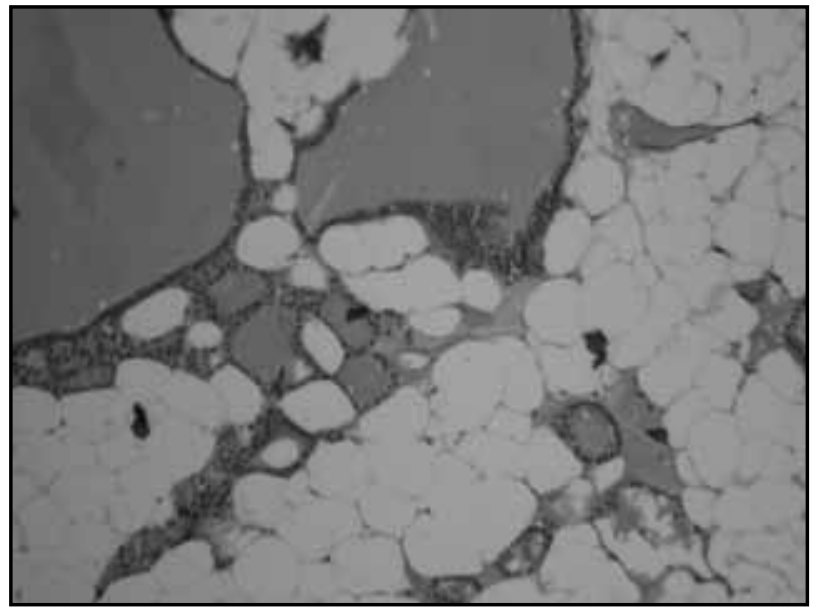

Figura 2 - Adenolipoma de tireoide (HE 100x)

Folículos tireoidianos com coloide e tecido adiposo unilocular intimamente associado. $H E$ : hematoxilina e eosina.

as unidades foliculares tireoidianas, caracterizando-se também pela presença de cápsula envoltória. Essa composição em certos tumores pode variar de $10 \%$ a $90 \%$ de tecido adiposo e, por isso, sua detecção por métodos de imagem pode variar amplamente. As nodulações são elásticas, não aderentes a planos profundos e sua inatividade endócrina não interfere de forma alguma na função glandular ${ }^{(4)}$.

A lesão acomete preferencialmente mulheres com idade média de 53,4 anos ${ }^{(5,7)}$.

A apresentação clínica é a de um expressivo aumento do volume cervical, podendo ser lento e insidioso, associado muitas vezes à sintomatologia compressiva local.

A avaliação laboratorial não evidencia alteração hormonal, presumindo a integridade do eixo hipotálamo-hipófise-tireoide, demonstrado por níveis normais de hormônio liberador de tireotrofina (TRH), TSH e T4 e T3 livres.

Os exames de imagem podem sugerir o diagnóstico de adenolipoma ao mostrarem a natureza lipídica da lesão, geralmente com isoecogenicidade na ecografia e hipointensidade na tomografia computadorizada ${ }^{(11)}$. A ressonância magnética confirma a natureza adiposa da lesão ${ }^{(3)}$. A cintilografia, utilizando o radiotraçador lodo 131 marcado com
Tecnécio-99 meta-estável, revela hipocaptação difusa de toda a glândula. A PAAF pode revelar adipócitos e células foliculares. Entretanto, se não for perfeitamente realizada, o resultado poderá ser inconclusivo ${ }^{(3,4,9-11)}$.

Histologicamente, são evidenciados folículos tireoidianos revestidos por epitélio cúbico, disposto em única camada, limitando espaços esféricos repletos de coloide, com tamanhos variados. Entre os folículos tireoidianos, observam-se frequentemente pequenos acúmulos de células claras parafoliculares ou células $C$, que apresentam, entre si, tecido adiposo unilocular, resultando em uma difusa infiltração estromal tireoidiana pelo tecido adiposo.

A origem do tecido adiposo na glândula tireoide não é bem esclarecida. Alguns autores admitem que ocorra inclusão de tecido adiposo na tireoide durante sua embriogênese e que o adenolipoma seria uma neoplasia verdadeira com a proliferação do tecido adiposo. Outros autores sugerem a origem metaplásica a partir de fibroblastos ${ }^{(9)}$. Trites ${ }^{(10)}$ descreveu uma rara síndrome constituída pela associação de tireolipoma, timolipoma e farigolipoma.

O surgimento da neoplasia dependeria de fatores que influenciam e afetam a embriogênese durante a formação das fendas faríngeas e arcos faríngeos ${ }^{(9,10)}$.

Por ser uma rara entidade, indolente e de prognóstico favorável, o adenolipoma deve ser distinguido de determinadas condições patológicas em que há presença de tecido adiposo unilocular associado ao tireoidiano, como bócio amiloide, tireoidite linfocítica, lipoadenomatose difusa tireoidiana, hiperplasia nodular, doença de Cowden, lipossarcoma, timo intratireoidiano e paratireoides intratireoidianas ${ }^{(11)}$. Os lipomas podem, eventualmente, mimetizar nódulos solitários ou múltiplos ao se proliferarem em direção à tireoide ${ }^{(2)}$. O tratamento do adenolipoma é cirúrgico e as indicações para sua ressecção são as mesmas de qualquer outra tumoração benigna tireoidiana, como o bócio coloide: compressão extrínseca de estruturas adjacentes e motivação estética devido à proeminência da região cervical anterior ${ }^{(7)}$.

\section{Referências}

1. BORGES, A.; CATARINO, A. Adenolipoma of thyroid gland. Radiology, v. 225, p. 746-50, 2002.

2. BUTLER, S.; OERTEL, Y. Lipomas of anterior neck simulating thyroid nodules: diagnosis by fine-needle aspiration. Diagn Cytopathol, v. 8, p. 528-53, 1992.
3. DEMIRPOLAT, G. et al. Radiologic and cytologic findings in a case of thyrolipoma. Am J Neuroradiol, v. 23, p. 1640-1, 2002.

4. GNEPP, D. R.; OGORZALEK, J. M.; HEFFES, C. S. Fat containing tumor of the thyroid gland. Am J Surg Pathol, v. 13, p. 605-12, 1989. 
5. HARACH, H. R. et al. Thyroid pathologic findings in patients with Cowdendisease. Ann Diagn Pathol, v. 6, p. 331-40, 1999.

6. HJORTH, L.; THOMSEM, L. B.; NIELSEN, V. T. Adenolipoma of the thyroid gland. Histopathology, v. 10, p. 91-6, 1986.

7. KITAGAWA, W. et al. Adenolipoma of the thyroid gland: report of a case. Surg Today, v. 34, p. 593-6, 2004.

8. LAFORGA, J. B.; VIERNA, J. Adenoma of thyroid gland containing fat (thyrolipoma): report of a case. J Laryngol Otol, v. 110, p. 1088-9, 1996.
9. ROSAI, J.; CARCANGIU, M. L.; DELELLIS, R. A. Atlas of tumor pathology: tumors of the thyroid gland. Third series, fascicle 5. Washington, DC: Armed Forces Institute of Pathology, 1992.

10. TRITES, A. E. Thyrolipoma, thymolipoma and pharyngeal lipoma: a syndrome. Can Med Assoc J, v. 95, p. 12549, 1996.

11. VELOZA, A. et al. Adenolipoma da tiróide. Acta Med Port, v. 23, p. 277-80, 2010. 